\title{
Extraction and analysis of abandoned farmland: A case study of Qingyun and Wudi counties in Shandong Province
}

\author{
XIAO Guofeng ${ }^{1,2,3},{ }^{*}$ ZHU Xiufang ${ }^{1,2,3}$, HOU Chenyao ${ }^{2}$, XIA Xingsheng ${ }^{1}$
}

1. Key Laboratory of Environmental Change and Natural Disaster of Ministry of Education, Faculty of Geographical Science, Beijing Normal University, Beijing 100875, China;

2. State Key Laboratory of Earth Surface Processes and Resource Ecology, Beijing Normal University, Beijing 100875, China;

3. Beijing Engineering Research Center for Global Land Remote Sensing Products, Institute of Remote Sensing Science and Engineering, Beijing Normal University, Beijing 100875, China

\begin{abstract}
Rapid urbanization and continuous loss of rural labor force has resulted in abandonment of large areas of farmland in some regions of China. Remote sensing technology can indirectly help detect abandoned farmland size and quantity, which is of great significance for farmland protection and food security. This study took Qingyun and Wudi counties in Shandong Province as a study area and used CART decision tree classification to compile land use maps of 1990-2017 based on Landsat and HJ-1A data. We developed rules to identify abandoned farmland, and explored its spatial distribution, duration, and reclamation. CART accuracy exceeded 85\% from 1990-2017. The maximum abandoned farmland area was 5503.86 ha during 1992-2017, with the maximum rate being $5.37 \%$. Farmland abandonment rate was the highest during 1996-1998, and abandonment trend decreased year by year after 2006. Maximum abandonment duration was 15 years (1992-2017), mostly within 4 years and only a few exceeded 10 years. From 1993-2017, the maximum reclaimed abandoned farmland was 2022.3 ha, and the minimum $\sim 20$ ha. The maximum reclamation rate was $67.44 \% \mathrm{~m}$, with annual average rate being $31.83 \%$. This study will help analyze farmland abandonment driving forces in the study area and also provide references to identify abandoned farmland in other areas.
\end{abstract}

Keywords: CART; abandonment; reclamation; farmland; Shandong Province; Landsat data

\section{Introduction}

Rapid urbanization has changed land use types and population distributions, and as rural population continues to decrease large arable land areas have been abandoned ( $\mathrm{Li}$ and Zhao,

Received: 2018-09-10 Accepted: 2018-11-08

Foundation: The National High Resolution Earth Observation System (The Civil Part) Technology Projects of China; State Key Laboratory of Earth Surface Processes and Resource Ecology, No.2017-FX-01(1)

Author: Xiao Guofeng, Master Candidate, specialized in land use change monitoring research. E-mail: xiao_gf@mail.bnu.edu.cn

"Corresponding author: Zhu Xiufang, PhD and Associate Professor, E-mail: zhuxiufang@bnu.edu.cn 
2011). Abandonment is one of the most important forms of cultivated land use change. Under the joint action of economic and natural factors, land production operators stop or reduce cultivation for varying periods, leaving cultivated land barren or unused (Huang et al., 2008).

The overall quality of cultivated land in China is poor compared with other countries, the amount of cultivated land per capita is small (Qi, 2009), and the area of sloping farmland is large (Hou et al., 2004). Large areas of farmland have been abandoned in some regions of China (Zhang et al., 2014; Shi, 2015). Farmland abandonment not only aggravates the contradiction between man and land, but also challenges national food security. Many studies have shown that farmland abandonment also impacts biodiversity (Queiroz et al., 2014), soil quality (Molinillo et al., 1997; Bakker et al., 2008), carbon cycle (Vuichard et al., 2008; Batllebayer et al., 2010), environment (Macdonald et al., 2000), etc. Therefore, the spatial distribution of abandoned farmland can provide the basis to analyze abandoned farmland environmental impacts.

There is no China-wide measurement for farm abandonment and hence the current extent of abandonment is not well known. Spatial and temporal resolutions of remote sensing image have greatly improved with rapid remote sensing technology developments. High temporal and spatial resolution remote sensing images can not only extract abandoned land size and quantity, but also help identify abandonment trends and driving factors. Alcantara et al . (2012) used support vector machine (SVM) models to map abandoned agricultural land at broad scales across Eastern Europe and the former Soviet Union, based on the normalized difference vegetation index (NDVI) and reflectance bands (NASA Global MODIS Terra and Aqua 16-Day Vegetation Indices for 2003-2008, 250 m resolution) and phenology metrics calculated by TIMESAT. Overall classification accuracy for abandoned agricultural land was 65\%. Yusoff et al. (2017) used a SPOT-6 satellite images to extract and classify abandoned oil palm areas and multi-temporal Landsat Operational Land Imager (OLI) imagery to develop the phenology of abandoned oil palm sites. They were able to identify waste oil palm areas with $92 \% \pm 1 \%$ accuracy. Alcantara et al. (2013) used MODIS NDVI time series data to extract abandoned farmland distributions for Central and Eastern Europe 2004-2006, and produced abandoned area maps. Abandoned farmland was widespread, totaling 52.5 million hectares (Mha). Baumann et al. (2011) used an SVM approach based on Gaussian kernel functions to extract abandoned farmland from 1986-2008 Landsat images for western Ukraine. Abandonment in the study area was widespread (56\%), with approximately 6600 $\mathrm{km}^{2}(30 \%)$ of farmland used after 1991. Kuemmerle et al. (2009) used Landsat TM/ETM+ images to produce land use coverage maps to extract the range of abandoned farmland in southern Romania from 1990 to 2005, and found that the rate of abandonment was $21.1 \%$. Estel et al. (2015) used MODIS time series data to extract abandoned farmland for Europe 2001-2012 based on random forest classification and detected approximately 128.7 Mha of fallow land (24.4\% of all farmland). Ma (2010) used land use change data to extract the amount of abandoned farmland, abandonment speed, and abandonment rate for Hollinger County, Inner Mongolia, 1996-2009. Cheng (2011) analyzed the accuracy for three methods to extract abandoned farmland in Huidong, Haifeng, and Lufeng counties of Guangdong Province, establishing an interpretation mark based on NDVI time series features and spectral features. Extracting abandoned farmland based on NDVI time series features provided 
the best outcomes. Shi and Xu (2016) extracted farmland from topographical maps for 2002 and current land use maps for 2011, and superposed farmland layers for these periods to provide distribution maps for abandoned farmlands 2002-2011 in typical counties of Chongqing. Farmland abandonment rates in Shizhu, Wushan, and Youyang counties were $14.0 \%, 19.9 \%$, and $19.2 \%$, respectively for 2011 . Niu et al. (2017) used four Landsat-8 OLI images from spring and autumn of 2013 and 2015 to obtain abandoned farmland spatial and temporal distribution for Zilu Town, Luoshan County, Henan Province. They found that interannual abandoned farmland area accounted for $7.45 \%$ of total Zilu Town farmland area, and seasonal abandoned farmland for $14.33 \%$.

Most previous studies identified abandoned farmland using two temporal remote sensing images. There has been little research on long time series abandoned land and almost none on reclamation of abandoned land. This study selected the plains area of Shandong Province (Qingyun and Wudi counties) and created classification maps using the CART decision tree classification algorithm for 1990-2017 based on Landsat and HJ-1A data. Abandoned farmland spatial distribution for 1992-2017 was extracted relative to arable farmland in the datum year (1990), according to definition and recognition rules for abandoned farmland. We used GIS spatial statistical functions to calculate abandonment durations, and extract abandoned farmland reclamation. The results from this paper will not only help analyze driving forces underlying farmland abandonment in the study area, but also provide references to the identification of the abandoned farmland in other areas.

\section{Study area and data}

\subsection{Study area}

Figure 1 shows the selected study area: Qingyun and Wudi counties of Shandong, an eastern coastal province of China located at lower reaches and the Yellow River, ranging $34^{\circ} 22.9^{\prime} \mathrm{N}$ to $38^{\circ} 24.01^{\prime} \mathrm{N}$ and $114^{\circ} 47.5^{\prime} \mathrm{E}$ to $122^{\circ} 42.3^{\prime} \mathrm{E}$, covering 155.8 thousand $\mathrm{km}^{2}$, including 17 cities and 137 counties. Climate in Shandong Province generally belongs to warm temperate monsoon type with concentrated rainfall, with rain and heat tending to occur over the same period. Frost free period increases from northeast to southwest. Light resources are abundant and general heat conditions can identify the need of two crops a year. Shandong is one of the major food production provinces in China, mainly producing wheat, corn, rice, soybeans, cotton, and peanuts. Previous studies (Li et al., 1994; Du et al., 2015) revealed that serious arable land abandonment has occurred in Qingyun and Wudi counties.

\subsection{Data}

The data used in this study include $30 \mathrm{~m}$ resolution Landsat images 1990-2011 and 2013-2017 from US Geological Survey (USGS) (http://glovis.usgs.gov/), with $30 \mathrm{~m}$ resolution HJ-1A data obtained from China Resource Satellite Application Center (http:// www.cresda.com/CN/) replacing 7 Landsat images of 2012 due to visible stripes in these mages. Time series images for 1990-2017 were collected with 2 images in each year, i.e. 56 images over 28 years in total. Images were mainly collected for the same two periods each year: April to June and July to October. Table 1 shows specific image details. 


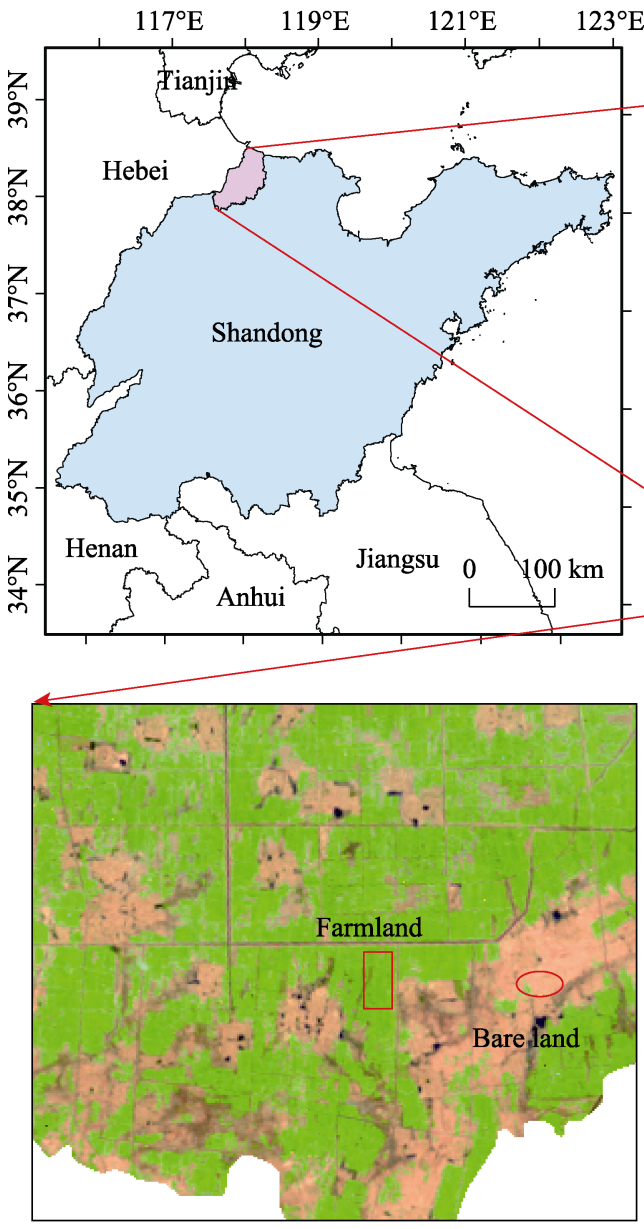

May 6, 1990 $117^{\circ} 20^{\prime} \mathrm{E} \quad 117^{\circ} 30^{\prime} \mathrm{E} \quad 117^{\circ} 40^{\prime} \mathrm{E} 117^{\circ} 50^{\prime} \mathrm{E} \quad 118^{\circ} 0^{\prime} \mathrm{E}$
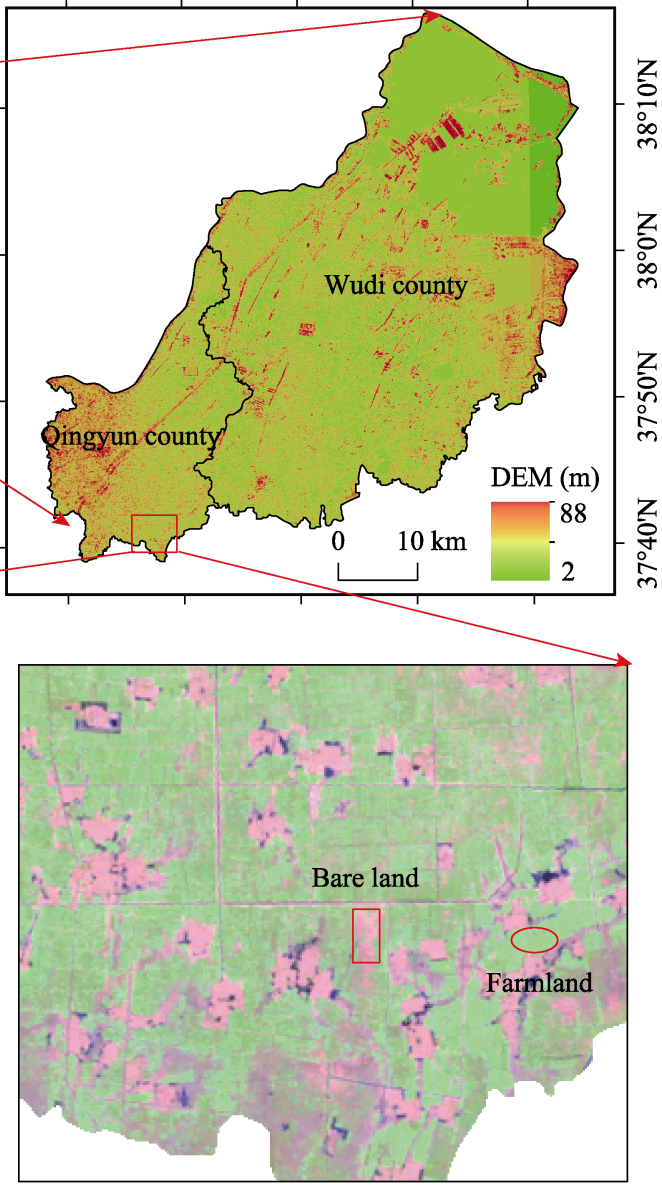

September 11, 1990

Figure 1 Location of Qingyun and Wudi counties, Shandogn Province, China

We also used $30 \mathrm{~m}$ resolution DEM data from the spatial data cloud (http://www.gscloud.cn/) as auxiliary data for classification. The $30 \mathrm{~m}$ resolution land classification product (1995, 2000, 2005, 2010, 2015) from Resource and Environment Data Cloud Platform (http://www.resdc.cn/) and Google Earth images were used as basic data to select training and validation samples.

\section{Methodology}

Figure 2 shows the study technical flowchart.

(1) TM and HJ-1A images were preprocessed to generate CART inputs.

(2) Google Earth image and previous high resolution land classification datasets were used to select training and validation samples for each image. Each image was classified using CART classification and accuracy was assessed for each classification map.

(3) The two classification maps for each year were combined to generate the final land use map for each year.

(4) Identification rules for abandoned farmland were established, based on identified 


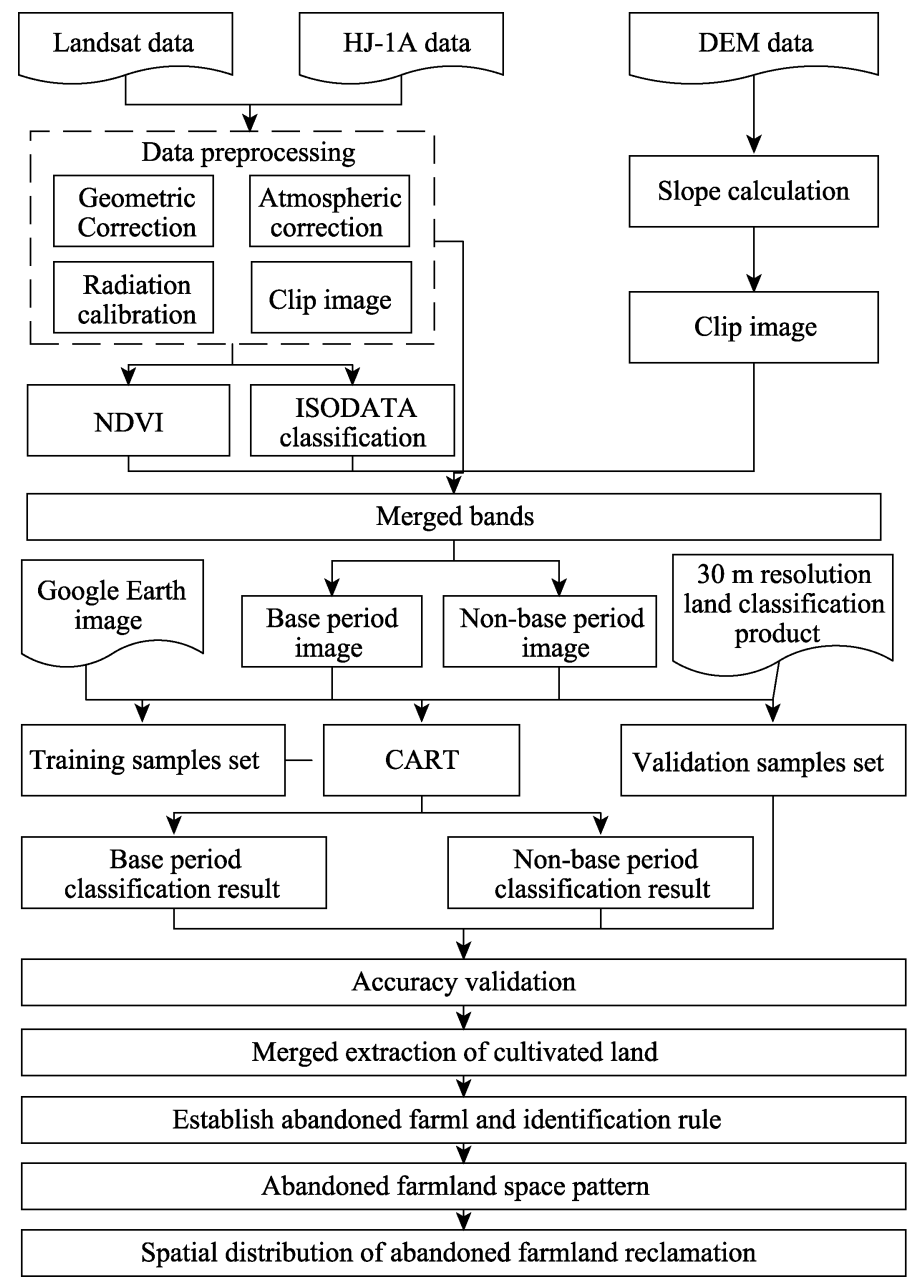

Figure 2 Technical flowchart of the study

abandonment and abandoned farmland spatial distributions were mapped.

(5) Spatial distribution maps for abandoned farmland reclamation were generated as time series abandonment maps.

\subsection{Data preprocessing}

TM and HJ-1A images were processed by geometric correction, radiometric calibration, atmospheric correction and image clipping, and then NDVI were calculated for each image. Then ISODATA unsupervised classification was performed using ENVI 5.3, with 10-15 classes and 10 iterations. The physical slope of the study area was calculated pixel by pixel using ArcGIS and DEM data. Finally, red, green, blue, and near infrared bands from each original image were combined with slope, NDVI, and ISODATA classification map to generate a new 7 band image for further processing.

\subsection{CART decision tree classification}

Many methods have been proposed to improve classification accuracy, including artificial 
neural networks, decision trees, support vector machine, etc. Decision tree classification can make full use of spectral features and other auxiliary image information, and effectively solve the problem for different objects having the same spectra and similar objects having different spectra (Chen et al., 2008). Common decision tree algorithms include ID3, C4.5, CART (Classification and Regression Tree), etc. (Zhao et al., 2005). The CART decision tree algorithm is simpler than most other decision tree systems and classification thresholds are determined from the training sample to the automatically established decision tree. CART performs well and has higher precision compared with neural network and support vector machine (Ma et al., 2017).

CART algorithm was proposed by Breiman et al. (1984) and is based on two division recursive segmentation techniques that divide the sample set into two subsets, i.e., each non-leaf node of the decision tree has two branches. Hence CART generates binary trees, with only yes or no outcomes for every step.

The CART algorithm uses the Gini coefficient (Gini Index) from economics as the criterion to select the best test variables. The selection criterion is that each subnode achieves the highest purity, i.e., all subnode elements belong to the same category. Assuming the dataset can be grouped into $m$ classes, the Gini coefficient for dataset $D$ can be expressed as

$$
\operatorname{Gini}(D)=1-\sum_{i=1}^{m} p_{i}^{2},
$$

where $p_{i}$ refers to probability of a given element belonging to $C_{i}$ and calculates by using $\left|C_{i, D}\right| /|D| \cdot \sum_{i=1}^{m} p_{i}^{2}$ is the sum of $p_{i}^{2}$.

\subsection{Land use/land cover mapping}

Considering the common practice for two crops per year in Shandong Province, two temporal high quality images should be selected for each year to improve cultivated land classification accuracy. From previous information, the two growing periods should be April to June and July to October. However, sowing ranges in cultivated farmland are inconsistent throughout the year. A pixel classified as cultivated land in the first temporal image may be bare land in the second temporal image and vice versa (Figure 3). Therefore, we merged identified farmland from each image for a given year to obtain the final farmland for the year. First, we classified the two temporal images in each year into six classes: farmland, woodland, grassland, water body, buildings, and bare land. Second, we validated the (two) classification map accuracy and used the classification map with the highest accuracy as the base map. Finally, we extracted farmland classified pixels from the other classification map to replace pixels in the same location that were classified as non-farmland in the base map (Figure 3).

\subsection{Abandoned farmland identification}

Some studies have defined arable land not cultivated for more than one year as abandonment, whereas others considered a single season as sufficient (Huang et al., 2008; Li and Li, 2016; Smaliychuk et al., 2016). This current study considered arable land barren for two or more years to be abandoned, while arable land barren for less than one year (including one year) 


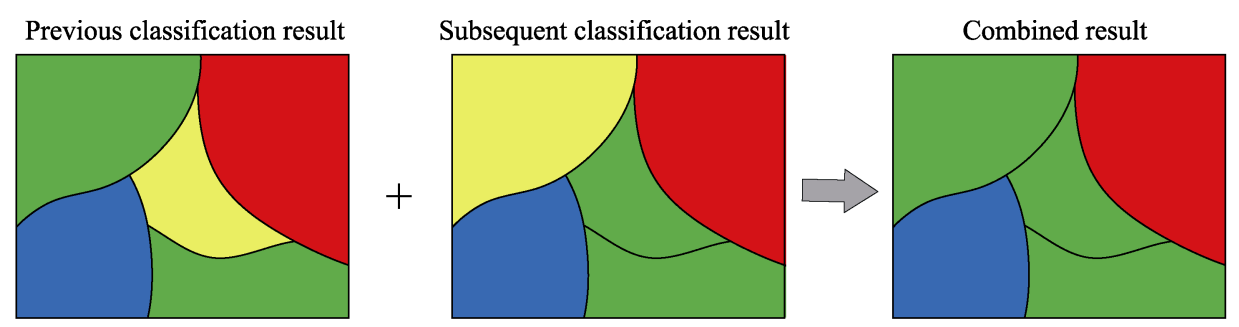

Note: Green represents cultivated land; yellow represents bare land; blue represents water; red represents building land

Figure 3 Example map of farmland extraction

was defined as fallow. Therefore, we set up the following identification rules for abandoned farmland. We used identified farmland from 1990 as the baseline and determined land use/land cover (LULC) change for each farmland pixel (T) year by year. If pixel T LULC type is farmland for a given year, then it was not abandoned in that year; if LULC type changed to water body, building area or woodland from the previous year, then it was not classed as abandoned; if LULC type changed to barren land or grassland, abandonment may have occurred. After the arable land is barren, its initial state becomes bare land. As time goes on, it gradually becomes grassland. Therefore, grassland is also suspected abandonment. However, conversion of arable land to grassland was quite rare in the study area. Therefore, this situation was ignored. The range of suspected abandoned farmland was identified year by year based on the above rules. Then, for a target year ( $\mathrm{t}$ ), if pixel $\mathrm{T}$ was identified as suspected abandoned farmland in the former two years $(\mathrm{t}-1$ and $\mathrm{t}-2)$, it was regarded as being abandoned in the target year.

Thus, time series abandoned farmland distribution maps 1992-2017 were obtained. Abandonment duration was calculated pixel by pixel based on these maps, and the abandonment rate was calculated as the proportion of abandoned farmland year by year,

$$
P_{a}=\frac{A_{t}}{A_{0}} \times 100 \%,
$$

where $P_{a}$ is abandonment rate, $A_{i}$ is the area of abandoned farmland in the year $t$, and $A_{0}$ is the area of farmland identified in the base year (1990).

\subsection{Abandoned farmland reclamation}

Cultivated land is the foundation for agricultural production. Large areas of abandoned farmland seriously hindered agricultural production and economic development. Restoration of abandoned land is the key to solve this problem. Restoration is the process of restoring abandoned farmland into arable land. The rule to identify a pixel as reclaimed was simple: if pixel $\mathrm{T}$ was identified as abandoned in year $\mathrm{t}-1$ but identified as farmland in the target year $\mathrm{t}$, then it was classified as reclaimed. Consequently, time series reclamation distribution maps 1993-2017 were obtained and the reclamation rate was calculated as the proportion of reclaimed farmland year by year,

$$
P_{r}=\frac{A_{t+1}^{\prime}}{A_{t}} \times 100 \%,
$$

where $P_{r}$ is reclamation rate, and $A_{t+1}^{\prime}$ is the area of reclaimed land identified in the year $t+1$. 


\section{Results}

\subsection{CART decision tree classification and validation}

Time series images 1990-2017 from TM and HJ-1A data were used to make LULC maps using the CART decision tree method, as shown in Figure 4. Figure 5 shows 8 exemplar LULC maps. The water body area has gradually increased with economic development, and most bare land near the sea has been converted into ponds. Building areas have expanded year by year, demonstrating urbanization, and the area of unused land was gradually reduced. Particularly in recent years, bare land has been utilized and transformed into water, building, and woodlands, except near the edge of the beach.

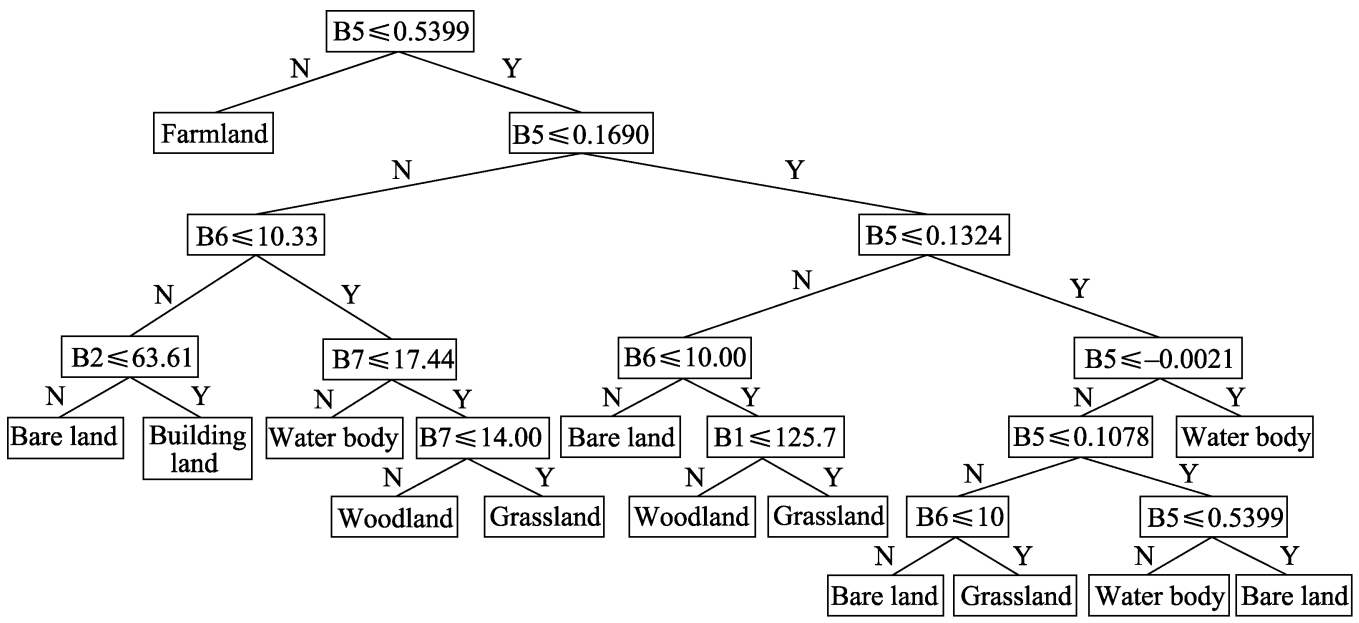

Figure 4 Decision tree (B1-B7 correspond to the seven bands of the composite image)

We used Google Earth images with similar acquisition times to the TM and HJ images and existing $30 \mathrm{~m}$ resolution land classification product as auxiliary data to select validation samples for each classification map, and then evaluated map accuracy using confusion matrices, as shown in Table 1. Overall classification accuracy ranged between $83.5 \%-94.2 \%$ over whole study period (1990-2017), with base image classification accuracy exceeding $85 \%$.

Farmland classification from 1990 was the base data, hence its accuracy is crucial to abandoned land extraction and identification. Therefore, we selected a large number of training samples from 1990 images, and carefully checked them. Classification accuracy for the two 1990 images was $92.5 \%$ and $94.2 \%$, respectively, which confirmed the 1990 data was suitable as farmland base data.

\subsection{Abandoned farmland identification}

Time series LULC classification maps were obtained using the CART algorithm, and then the spatial distribution maps of abandoned farmland for 1992-2017 were obtained using the identification rules for abandoned farmland. Figure 6 shows some examples of abandoned farmland distribution maps. Farmland abandonment mainly occurred in the central part of the study area. 



Figure 5 Land use classification results in Qingyun and Wudi counties

Table 2 shows the area of abandoned farmland and abandonment rate calculated year by year. Abandonment rates were higher in 1996, 1997, and 1998, with maximum abandonment rate 5.37\% in 1997. Abandonment rates in 1994, 2003, 2013, 2014, 2016, and 2017 were all less than $0.4 \%$.

Figure 9a shows abandonment trend 1992-2017. The area of abandoned farmland in 1997 was the largest (5503.86 ha) and the smallest in 2016 (226.44 ha). The change varied over the study period. 1992-1994, 1994-1997, 1997-2003, 2003-2006 and 2006-2017 alternated reducing and increasing around the overall trend. In particular, the area of abandoned farmland in 2016 and 2017 was less than 300 ha, indicating that abandonment was gradually decreasing and could be considered controlled. 
Table 1 Image acquisition time and classification accuracy

\begin{tabular}{|c|c|c|c|c|c|c|c|c|c|c|c|}
\hline \multirow{2}{*}{ Year } & \multicolumn{2}{|c|}{$\begin{array}{c}\text { Date } \\
\text { (month-day) }\end{array}$} & \multirow{2}{*}{$\begin{array}{c}\text { Date of } \\
\text { base image }\end{array}$} & \multicolumn{2}{|c|}{$\begin{array}{c}\text { Overall accuracy } \\
(\%)\end{array}$} & \multirow{2}{*}{ Year } & \multicolumn{2}{|c|}{$\begin{array}{c}\text { Date } \\
\text { (month-day) }\end{array}$} & \multirow{2}{*}{$\begin{array}{c}\text { Date of } \\
\text { base image }\end{array}$} & \multicolumn{2}{|c|}{$\begin{array}{c}\text { Overall accuracy } \\
(\%)\end{array}$} \\
\hline & Date1 & Date2 & & Date1 & Date2 & & Date1 & Date2 & & Date1 & Date2 \\
\hline 1990 & 0506 & 0911 & 0911 & 92.5 & 94.2 & 2004 & 0528 & 1003 & 1003 & 87.5 & 89.1 \\
\hline 1991 & 0509 & 1006 & 0509 & 90.3 & 84.3 & 2005 & 0515 & 0904 & 0904 & 87.7 & 89.9 \\
\hline 1992 & 0527 & 1018 & 1018 & 91.7 & 91.8 & 2006 & 0502 & 0907 & 0907 & 89.1 & 90.4 \\
\hline 1993 & 0514 & 0903 & 0903 & 86.0 & 92.1 & 2007 & 0505 & 0809 & 0809 & 84.0 & 90.9 \\
\hline 1994 & 0517 & 0906 & 0517 & 92.6 & 91.4 & 2008 & 0608 & 0827 & 0827 & 84.2 & 88.3 \\
\hline 1995 & 0504 & 0824 & 0504 & 93.7 & 88.4 & 2009 & 0526 & 0830 & 0830 & 86.9 & 89.2 \\
\hline 1996 & 0522 & 1013 & 0522 & 86.4 & 83.5 & 2010 & 0427 & 0614 & 0427 & 90.1 & 86.4 \\
\hline 1997 & 0423 & 1016 & 1016 & 85.3 & 88.7 & 2011 & 0516 & 0820 & 0820 & 86.8 & 86.9 \\
\hline 1998 & 0528 & 0629 & 0629 & 85.2 & 85.2 & 2012 & 0527 & 0928 & 0928 & 89.6 & 90.2 \\
\hline 1999 & 0429 & 0803 & 0803 & 90.4 & 92.4 & 2013 & 0521 & 0825 & 0825 & 84.1 & 91.1 \\
\hline 2000 & 0501 & 0906 & 0906 & 85.3 & 88.6 & 2014 & 0508 & 0929 & 0929 & 86.5 & 90.9 \\
\hline 2001 & 0418 & 0909 & 0909 & 87.0 & 92.2 & 2015 & 0425 & 0815 & 0815 & 87.9 & 90.0 \\
\hline 2002 & 0710 & 1014 & 0710 & 91.7 & 86.4 & 2016 & 0513 & 1004 & 0513 & 91.4 & 84.2 \\
\hline 2003 & 0627 & 0915 & 0915 & 88.8 & 91.1 & 2017 & 0516 & 1023 & 1023 & 91.5 & 91.4 \\
\hline
\end{tabular}

Table 2 Abandoned farmland statistics in Qingyun and Wudi counties of 1992-2017

\begin{tabular}{lccccc}
\hline Year & Abandonment area (ha) & Abandonment rate (\%) & Year & Abandonment area (ha) & Abandonment rate $(\%)$ \\
\hline 1992 & 3526.74 & 3.44 & 2005 & 2564.73 & 2.50 \\
1993 & 2355.03 & 2.30 & 2006 & 3287.61 & 3.21 \\
1994 & 286.47 & 0.28 & 2007 & 2998.8 & 2.92 \\
1995 & 650.34 & 0.63 & 2008 & 2850.75 & 2.78 \\
1996 & 4372.47 & 4.26 & 2009 & 1851.66 & 1.81 \\
1997 & 5503.86 & 5.37 & 2010 & 1307.16 & 1.48 \\
1998 & 5288.40 & 5.16 & 2011 & 1519.11 & 2.36 \\
1999 & 2255.31 & 2.20 & 2012 & 2418.12 & 0.33 \\
2000 & 1097.01 & 1.07 & 2013 & 341.46 & 0.29 \\
2001 & 628.02 & 0.61 & 2014 & 292.59 & 1.25 \\
2002 & 842.04 & 0.82 & 2015 & 1285.74 & 0.22 \\
2003 & 356.31 & 0.35 & 2016 & 226.44 & 0.26 \\
2004 & 650.43 & 0.63 & 2017 & 263.97 & \\
\hline
\end{tabular}

Figure 7 shows abandonment duration and Table 3 shows abandoned area for different duration. Abandonment duration ranged from 1-15 years over 1992-2017. Long duration abandonment mainly occurred in the northeastern and eastern parts of the study area, 

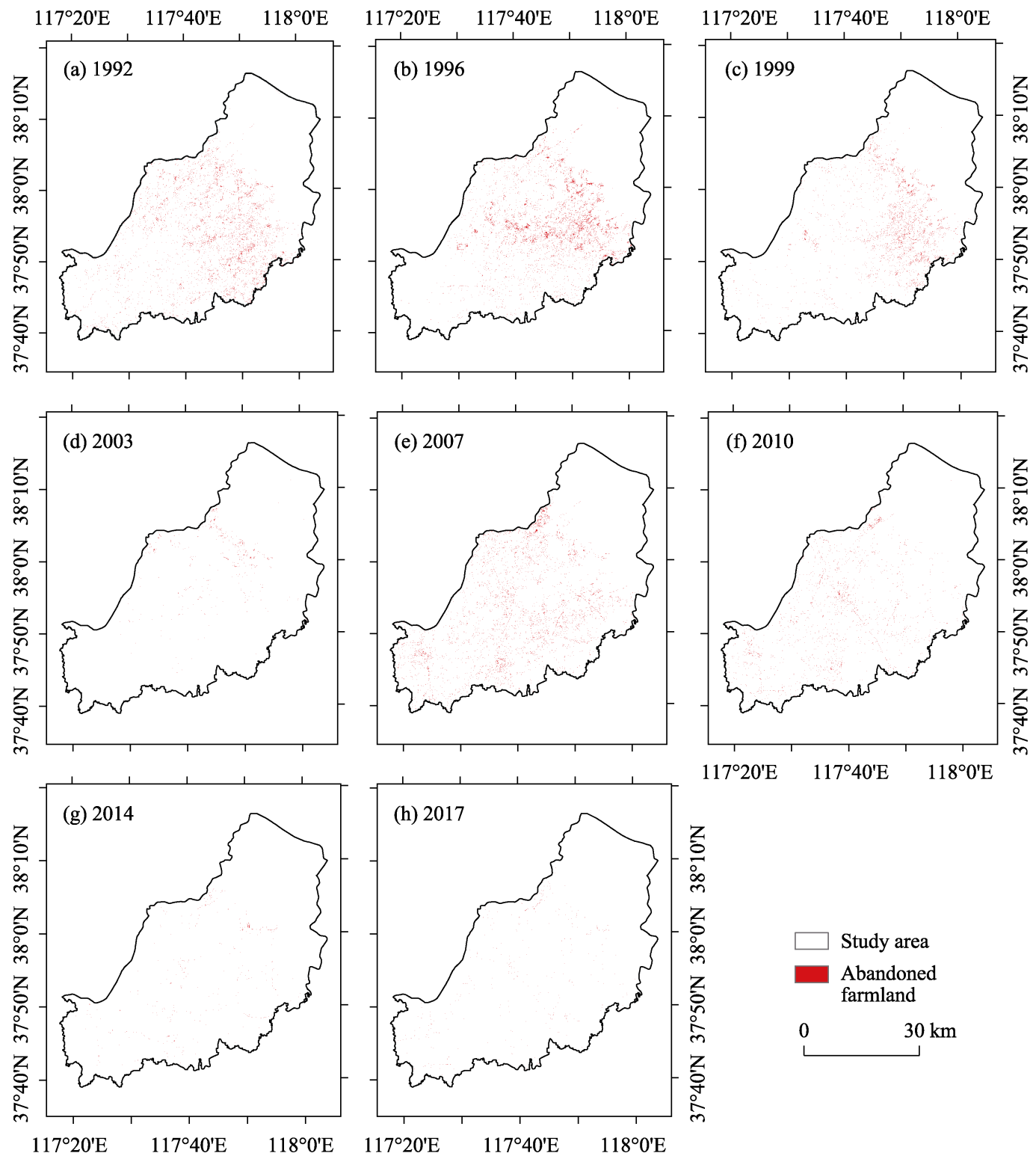

Study area

Abandoned

farmland

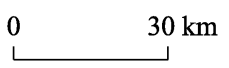

Figure 6 Distribution of abandoned farmland in Qingyun and Wudi counties

Table 3 Abandoned farmland area for the duration of abandonment in Qingyun and Wudi counties

\begin{tabular}{cc||cc||cc}
\hline $\begin{array}{c}\text { Abandonment } \\
\text { duration (year) }\end{array}$ & $\begin{array}{c}\text { Abandonment } \\
\text { area (ha) }\end{array}$ & $\begin{array}{c}\text { Abandonment } \\
\text { duration (year) }\end{array}$ & $\begin{array}{c}\text { Abandonment } \\
\text { area (ha) }\end{array}$ & $\begin{array}{c}\text { Abandonment } \\
\text { duration (year) }\end{array}$ & $\begin{array}{c}\text { Abandonment } \\
\text { area (ha) }\end{array}$ \\
\hline 1 & 11183.67 & 6 & 501.21 & 11 & 17.64 \\
2 & 5278.32 & 7 & 288.9 & 12 & 8.46 \\
3 & 2846.25 & 8 & 159.21 & 13 & 1.44 \\
4 & 1587.15 & 9 & 82.26 & 14 & 0.99 \\
\hline
\end{tabular}




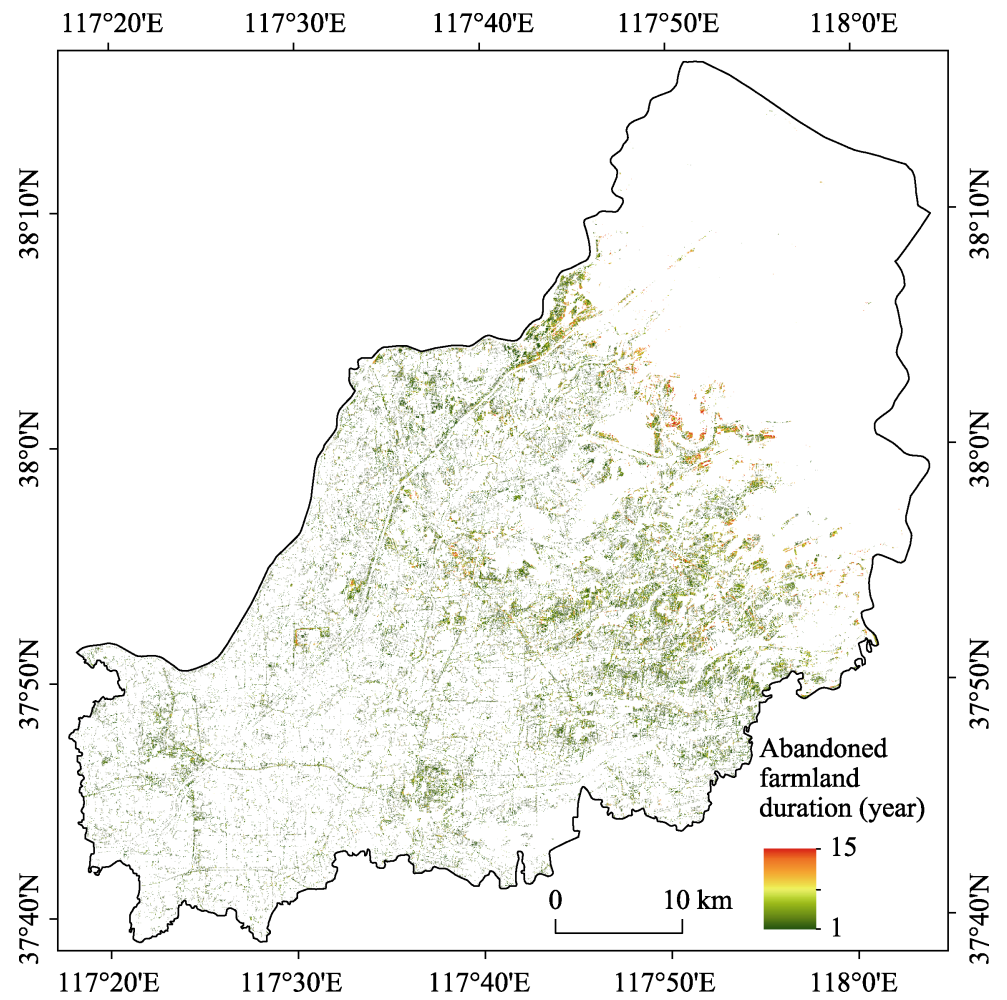

Figure 7 Distribution of abandoned farmland duration in Qingyun and Wudi counties of 1992-2017

whereas duration in the southwest was relatively short. Most abandoned farmland was abandoned for 4 years, with only a small amount abandoned for more than 10 years. The area of farmland abandoned for 1 year was the largest $(11,183.67 \mathrm{ha}, 48.81 \%$ of the total abandoned farmland area). Total abandoned farmland area with duration less than 4 years was $20,895.39$ ha $(91.20 \%$ of the total abandoned farmland).

Thus, abandonment duration for most farmland was short, and abandoned farmland area decreased with increasing duration. This may be attributed to three reasons.

1. Abandoned farmland was gradually restored to cultivated land, reducing the duration of continuous abandonment.

2. Farmland abandonment was successional: cultivated land $\rightarrow$ bare land $\rightarrow$ grassland $\rightarrow$ sparse shrub $\rightarrow$ woodland. When farmland is finally transformed into woodland, this is defined as an LULC change, and is not considered to be abandoned.

3. Rapid urbanization forced some farmland to transfer into building area. Due to lack of funds and other reasons, farmland transformed to abandoned land for many years, then when construction resumed, abandonment ceased.

\subsection{Abandoned farmland reclamation}

Farmland is an important land resource and abandonment is detrimental to food security and cultivated land protection. Hence reclamation of abandoned farmland is particularly important. We identified reclaimed pixels for 1993-2017 based on time series abandoned farmland 
and LULC maps. Figure 8 shows some examples of abandoned farmland reclamation. The distribution of reclamation was basically consistent with that of abandonment, mainly concentrated in the central part of the study area.
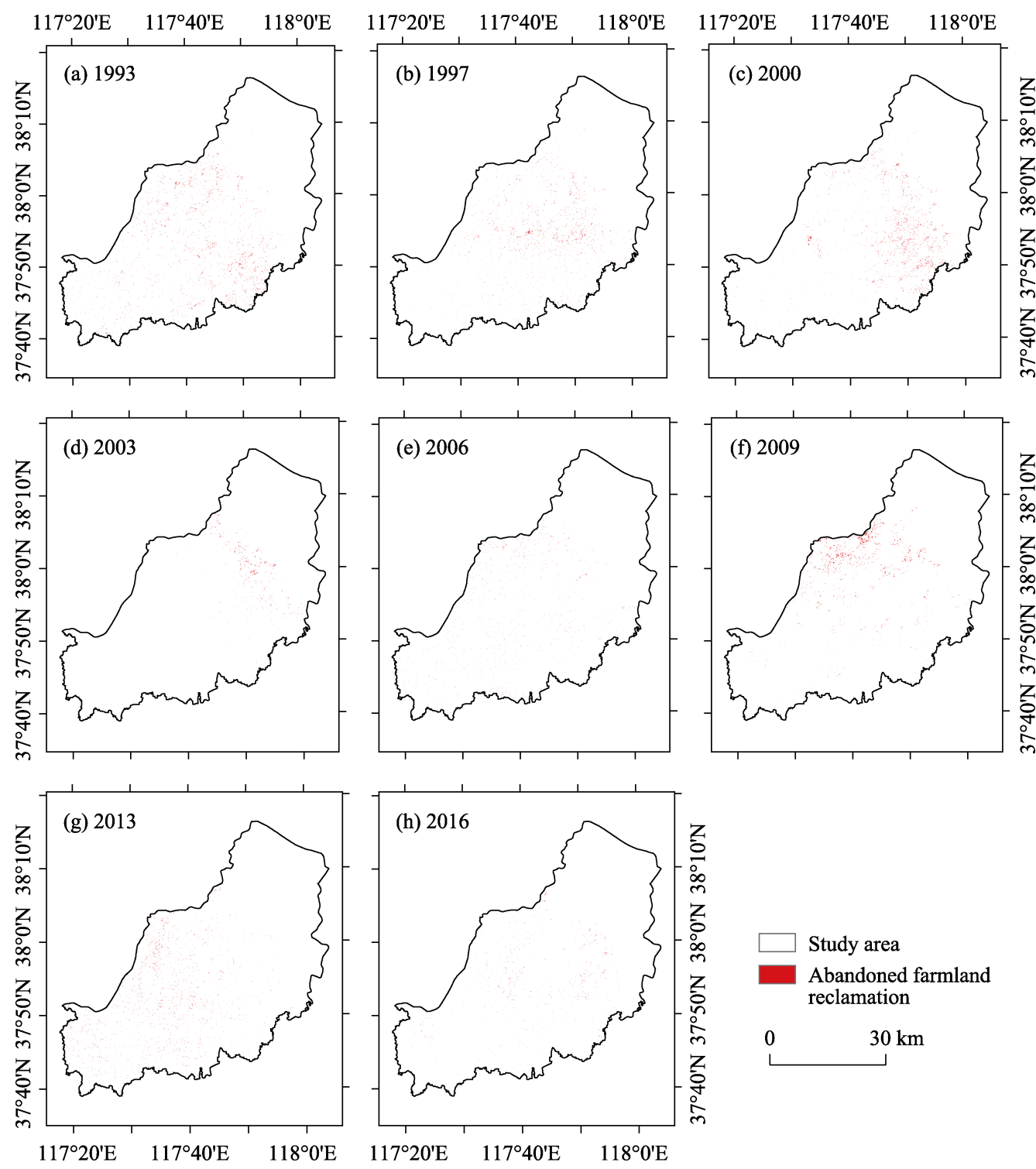

Figure 8 Reclamation of abandoned farmland in Qingyun and Wudi counties

Table 4 shows the area of reclaimed farmland and reclamation rate year by year and Figure $9 \mathrm{~b}$ shows reclamation trends 1993-2017. Reclaimed farmland in 2008 was the largest (2022.3 ha), and the smallest in 2014 (roughly $20 \mathrm{ha}$ ). Maximum reclamation rate also occurred in 2008 (67.44\%) with minimum in 2002 (4.61\%), and the average was $31.83 \%$. Only 4 years showed more than 50\%, 12 years more than 30\%, and 3 years less than $10 \%(2002$, 2014, and 2015). Reclamation exhibited a similar time pattern of reducing and increasing changes to abandonment (Figure 9b). 
Table 4 Statistics of abandoned farmland reclamation in Qingyun and Wudi counties of 1993-2017

\begin{tabular}{ccc||ccc}
\hline Year & Reclamation area (ha) & Reclamation rate (\%) & Year & Reclamation area (ha) & Reclamation rate (\%) \\
\hline 1993 & 1607.31 & 45.57 & 2006 & 431.28 & 16.82 \\
1994 & 1539.09 & 65.35 & 2007 & 603.72 & 18.36 \\
1995 & 89.10 & 31.10 & 2008 & 2022.30 & 67.44 \\
1996 & 217.08 & 33.38 & 2009 & 1252.89 & 43.95 \\
1997 & 1063.80 & 24.33 & 2010 & 281.79 & 15.22 \\
1998 & 852.30 & 15.49 & 2011 & 141.66 & 10.84 \\
1999 & 1010.52 & 19.11 & 2012 & 759.15 & 49.97 \\
2000 & 1381.68 & 61.26 & 2013 & 1056.69 & 43.70 \\
2001 & 266.49 & 24.29 & 2014 & 19.17 & 5.61 \\
2002 & 28.98 & 4.61 & 2015 & 20.52 & 7.01 \\
2003 & 400.68 & 47.58 & 2016 & 354.78 & 27.59 \\
2004 & 183.69 & 51.55 & 2017 & 99.36 & 43.88 \\
2005 & 141.30 & 21.72 & & & \\
\hline
\end{tabular}
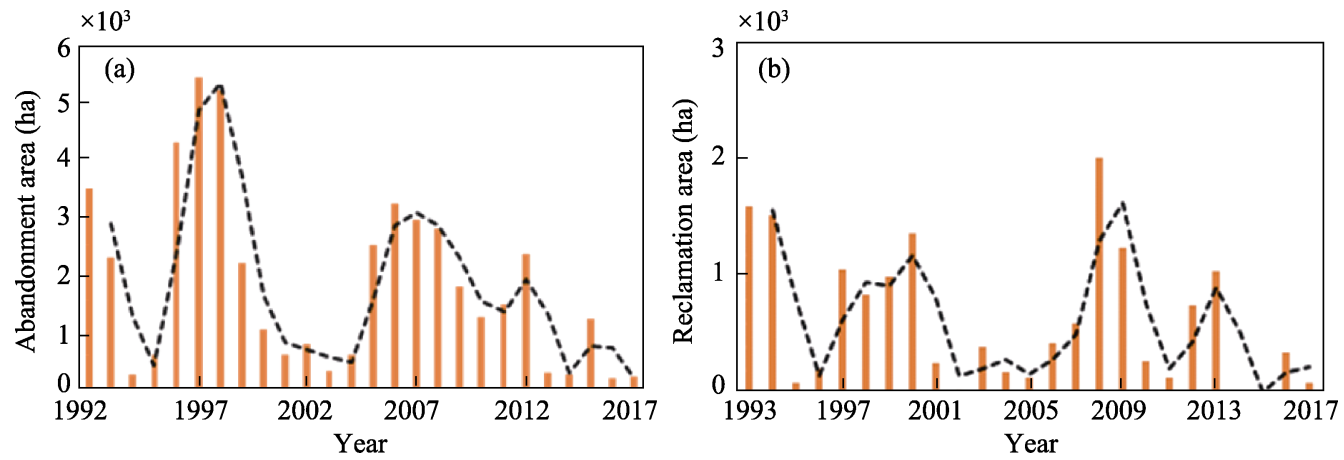

Figure 9 Statistical results of annual variation of abandoned farmland and reclaimed cultivated land in Qingyun and Wudi counties

\section{Conclusion and discussion}

\subsection{Conclusions}

This paper used the CART decision tree classification method based on $30 \mathrm{~m}$ spatial resolution time series remote sensing images to develop land use maps from 1990-2017, devise rules to identify abandoned farmland, and explore spatial distribution, duration, and reclamation area of abandoned farmland. Several conclusions could be drawn, as follows.

(1) Overall CART classification ranged between $83.5 \%-94.2 \%$ over whole study period (1990-2017), and base image classification accuracy exceeding 85\%. Classification accuracy for the two 1990 images was $92.5 \%$ and $94.2 \%$, respectively, verifying the images were suitable as farmland base data.

(2) Over the 26 years (1992-2017) study period, the largest area of annual abandoned farmland was 5503.86 ha and the smallest was 226.44 ha. Farmland abandonment rates for 1996, 1997, and 1998 were higher, with the maximum being 5.37\% in 1997. Abandonment rates were less than $0.4 \%$ for 6 years $(2003,2013,2014,2016$, and 2017). The area of aban- 
abandoned farmland decreased year by year over 2006-2017.

(3) In the past 25 years (1993-2017), the largest annual reclaimed area was 2022.3 ha and the smallest 20 ha. The maximum rate was $67.44 \%$, the minimum was $4.61 \%$, and the average was $31.83 \%$.

\subsection{Discussion}

Arable land is the most crucial material in agriculture. Arable land abandonment is closely related to ecological environment health and food security ( $\mathrm{Li}$ and $\mathrm{Li}, 2018$ ). Hence it is particularly important to determine the scale, quantity, duration, and reclamation for abandoned farmland. However, farmland abandonment is difficult to identify because it is driven by both natural and social factors, and abandoned farmland is usually fragmented and scattered. Small farmland patches are more vulnerable to abandonment (Lei, 2016), but spatial resolution of long time series remote sensing images is relatively low, and it is difficult to identify small abandoned land parcels in the low resolution images. On the other hand, high resolution long time series data is difficult to acquire, which poses significant challenges for abandoned farmland mapping at large scale.

This study collected $30 \mathrm{~m}$ spatial resolution time series images composed by Landsat and HJ-1A, combined the red, green, blue, and near infrared bands of each original image with slope, NDVI, and ISODATA classification map to generate new images with 7 bands, then classified each new image to provide LULC maps using CART. Identification rules for abandoned farmland were derived and abandoned farmland was mapped and analyzed. However, several problems should be acknowledged.

(1) There is currently no unified abandoned land definition. Various studies have considered many abandoned farmland definitions in different research areas. Some studies defined cultivated land unused for more than one year as abandoned, whereas other studies defined cultivated land unused for more than one season as abandoned, and other defined cultivated land unused for not less than two years as abandoned. This discrepancy has great influence on identification results. Considering the study area and previous investigations, this study defined abandoned farmland as cultivated land unused for two or more years.

(2) Vegetation succession on abandoned farmland is somewhat complicated. Farmland first changes to bare land after abandonment, then sparse grassland, followed by dense meadow. To protect the environment, local governments often introduce policies to return farmland to forests and grasslands. Therefore, it is difficult to determine abandoned land identification rules. This study did not consider returning farmland to forests and grasslands as abandonment, since this usually happens in mountainous areas and the study area focused on plains where farmland has little opportunity to directly convert to grassland. Collecting background details of returning farmland to forest will be useful to map abandoned farmland in mountainous areas.

(3) Image classification errors can be transferred to the final identification results. For example, crop and grass spectral characteristics are similar in spring across this study area, which could cause confusion errors during spring. However, their spectral characteristics differ in autumn, and they can be relatively easily distinguished. Therefore, we selected two temporal images for each studied year (April-June and July-October) to improve classification accuracy. It is also difficult to directly identify abandoned farmland from singe images 
per year. The current first created time series LULC maps and then derived identification rules to extract abandoned farmland. The LULC map errors will be transferred to abandoned farmland identification, which cannot be avoided. Thus, we reduce abandoned farmland extraction error by improving LULC map accuracy.

(4) It is difficult to directly assess abandoned farmland map accuracy. There are no statistical data on abandoned farmland. Previous studies mostly obtained small scale abandonment details (e.g. by village) using questionnaires or surveys. It is also difficult to obtain historical abandoned farmland distributions, although if abandoned land for the current year is extracted, actual abandoned samples can be investigated by field survey. Abandonment identification accuracy was indirectly assessed from image classification accuracy in this study due to the lack of real abandoned farmland data.

We must improve image classification accuracy to ensure abandoned farmland extraction accuracy and solve the problems discussed above. This study mainly used spectral information for classification. However, more information such as spatial location, should be introduced in the future to improve classification accuracy. Farmland cultivation is controlled by the natural environment and human factors (Shao et al., 2015; Li and Li, 2017). The number and optimal time for remote sensing images should be determined according to crop phenology calendars, which could reduce farmland omission errors. For example, areas with two crops per year should choose at least two temporal images, corresponding to the crop growth seasons, whereas area with three crops per year should choose at least three temporal images. Field surveys or questionnaires could also provide abandoned farmland validation samples to help improve abandoned farmland mapping accuracy, but this would require significant financial and human cost.

\section{References}

Alcantara C, Kuemmerle T, Baumann M et al., 2013. Mapping the extent of abandoned farmland in Central and Eastern Europe using MODIS time series satellite data. Environmental Research Letters, 8(3): 1345-1346.

Alcantara C, Kuemmerle T, Prishchepov A V et al., 2012. Mapping abandoned agriculture with multi-temporal MODIS satellite data. Remote Sensing of Environment, 124(2): 334-347.

Bakker M M, Govers G, Doorn A V et al., 2008. The response of soil erosion and sediment export to land-use change in four areas of Europe: The importance of landscape pattern. Geomorphology, 98(3/4): 213-226.

Batllebayer L, Batjes N H, Bindraban P S, 2010. Changes in organic carbon stocks upon land use conversion in the Brazilian Cerrado: A review. Agriculture Ecosystems \& Environment, 137(1): 47-58.

Baumann M, Kuemmerle T, Elbakidze M et al., 2011. Patterns and drivers of post-socialist farmland abandonment in Western Ukraine. Land Use Policy, 28(3): 552-562.

Breiman L, Friedman J H, Olshen R et al., 1984. Classification and regression trees. Biometrics, 40(3): 358.

Chen Yun, Dai Jinfang, Li Junjie, 2008. CART-based decision tree classifier using multi-feature of image and its application. Geography and Geo-Information Science, 24(2): 33-36. (in Chinese)

Cheng W F, 2011. Study on remote sensing survey method of abandoned farmland in South China [D]. Beijing: University of Chinese Academy of Sciences. (in Chinese)

Du W W, Xing H Y, Wang L H, 2015. Investigation on the problem of abandoned farmland in Qingyun County of Shandong Province. Rural Economy and Science-Technology, 26(11): 25-27. (in Chinese)

Estel S, Kuemmerle T, Alcántara C et al., 2015. Mapping farmland abandonment and recultivation across Europe using MODIS NDVI time series. Remote Sensing of Environment, 163: 312-325.

Hou Y K, Duan S G, Zhao S, 2004. Main Tree Species for Conversion of Cropland to Forest in China. Beijing: China Agricultural Press. (in Chinese) 
Huang L M, Zhang A L, Liu C W, 2008. Research on the agriculture land abandoning and its quantitative description. Journal of Xianning University, 28(3): 113-116, 121. (in Chinese)

Kuemmerle T, Müller D, Griffiths P et al., 2009. Land use change in Southern Romania after the collapse of socialism. Regional Environmental Change, 9(1): 1-12.

Lei H, 2016. The cultivated farmland abandonment and risk assessment based on characteristics of abandoned farmland: Illustrated by the case of Shehong Tuopai Town and Three Others [D]. Chengdu: Sichuan Normal University. (in Chinese)

Li J X, Lu J F, 1994. Investigation report on abandoned farmland in Shandong Province. Management of Rural Cooperative Economy, (8): 35-36. (in Chinese)

Li S F, Li X B, 2016. Progress and prospect on farmland abandonment. Acta Geographica Sinica, 71(3): 370-389. (in Chinese)

Li S F, Li X B, 2017. Global understanding of farmland abandonment: A review and prospects. Journal of Geographical Sciences, 27(9): 1123-1150.

Li S F, Li X B, 2018. Economic characteristics and the mechanism of farmland marginalization in mountainous areas of China. Acta Geographica Sinica, 73(5): 803-817. (in Chinese)

Li X B, Zhao Y L, 2011. Forest transition, agricultural land marginalization and ecological restoration. China Population Resources and Environment, 21(10): 91-95. (in Chinese)

Ma L L, 2010. Probe into the reasons of farmland abandoned in semi-arid regions based on remote sensing and the investigation of peasant household: A case study of Hollinger County in Inner Mongolia [D]. Huhhot: Inner Mongolia Normal University. (in Chinese)

Ma X, Wang X Y, Hu B, 2017. The cart automatic decision tree to multi-source remote sensing image classification based on ENVI: Taking Beijing as an example. Ningxia Engineering Technology, 16(1): 63-66. (in Chinese)

Macdonald D, Crabtree J R, Wiesinger G et al., 2000. Agricultural abandonment in mountain areas of Europe: Environmental consequences and policy response. Journal of Environmental Management, 59(1): 47-69.

Molinillo M, Lasanta T, Garcia-Ruiz J M, 1997. Research: managing mountainous degraded landscapes after farmland abandonment in the Central Spanish Pyrenees. Environmental Management, 21(4): 587-598.

Niu J Q, Lin H, Niu Y N et al., 2017. Analysis of spatial pattern and driving factors for abandoned arable lands in underdevelopment region. Transactions of the Chinese Society of Agricultural Machinery, 48(2): 141-149. (in Chinese)

Qi M H, 2009. Current situation and countermeasures of farmland protection in China. Agriculture \& Technology, 29(3): 1-3. (in Chinese)

Queiroz C, Beilin R, Folke C et al., 2014. Farmland abandoned: Threat or opportunity for biodiversity conservation? A global review. Frontiers in Ecology and the Environment, 12(5): 288-296.

Shao J A, Zhang S C, Li X B, 2015. The role of rural farmland transfer in preventing farmland abandonment in the mountainous areas. Journal of Geographical Sciences, 70(4): 636-649. (in Chinese)

Shi T C, 2015. Research on farmland abandonment scale and influencing factors in Chongqing mountain area [D]. Beijing: University of Chinese Academy of Sciences. (in Chinese)

Shi T C, Xu X H, 2016. Extraction and validation of abandoned farmland parcel in typical counties of Chongqing. Transactions of the Chinese Society of Agricultural Engineering, 32(24): 261-267. (in Chinese)

Smaliychuk A, Müller D, Prishchepov A V et al., 2016. Recultivation of abandoned agricultural lands in Ukraine: Patterns and drivers. Global Environmental Change, 38: 70-81.

Vuichard N, Ciais P, Belelli L et al., 2008. Carbon sequestration due to the abandoned of agriculture in the former USSR since 1990. Global Biogeochemical Cycles, 22(4): 1417-1430.

Yusoff N M, Muharam F M, Khairunniza-Bejo S, 2017. Towards the use of remote-sensing data for monitoring of abandoned oil palm lands in Malaysia: A semi-automatic approach. International Journal of Remote Sensing, 38(2): 432-449.

Zhang Y, Li X, Song W, 2014. Determinants of cropland abandoned at the parcel, household and village levels in mountain areas of China: A multi-level analysis. Land Use Policy, 41(4): 186-192.

Zhao P, Fu Y F, Zheng L G et al., 2005. CART based land use/cover classification of remote sensing images. Journal of Remote Sensing, 9(6): 708-716. 